\title{
Screening do potencial hidrogeniônico e toxicidade em Allium cepa de infusões populares frente a urolitíase por metodologia analítica
}

Screening of the hydrogenionic potential and toxicity of Allium cepa from popular infusions against urolithiasis by analytical methodology

Detección del potencial hidroiónico y la toxicidad de Allium cepa a partir de infusiones populares contra la urolitiasis mediante metodología analítica

\section{Resumo}

Na medicina moderna a utilização de plantas com fins terapêuticos é chamada fitoterapia e sua utilização é crescente frente a população em modo geral, pesquisadores e profissionais da área da saúde. Uma das aplicações populares é o uso de infusões para alterações nefrológicas em especial na formação de cálculos, ou ainda, litíase renal. Assim, frente a grande utilização popular de infusões o presente trabalho objetiva a avaliação de toxicidade e do potencial hidrogeniônico de infusão do caule de Equisetum arvense L. (Cavalinha), das flores de Hibiscus sabdariffa (Hibisco) e folhas de Persea americana (abacate). Para avaliação experimental, as amostras dos produtos naturais foram obtidas de forma comercial e o preparo das infusões foi adicionado água e levado a aquecimento até ponto de fervura. Para teste de toxicidade, em placa de cultivo de 96 poços foram adicionados $300 \mu \mathrm{L}$ da infusão em temperatura ambiente e inoculado uma semente por poço de Allium cepa e para realização do teste de potencial hidrogeniônico as infusões foram transferidas para recipiente de vidro e com o auxílio de um peagâmetro foram realizadas aferições do valor de pH durante 96 horas. Não foram identificadas alterações na germinação e crescimento nas infusões testadas. Quanto ao potencial hidrogeniônico a infusão de Cavalinha (E. arvense) apresentou acidificação do meio em $10 \%$ enquanto Hibisco (H. sabdariffa) $64 \%$ de acidificação e as folhas de abacate $21 \%$ de acidificação. Frente ao demonstrado, o consumo das infusões de Cavalinha, flores de Hibisco e de folhas de Abacate se mostrou seguro frente ao teste de Allium cepa e promissor para tratamento de urolitíase alcalina, além dos efeitos antioxidantes presentes na literatura. No entanto, pode ser prejudicial em casos da formação de urolitíase ácida.

Palavras-chave: Medicina tradicional; Medicina herbal; Fitoterapia; Urolitíase.

\footnotetext{
Abstract

In modern medicine, the use of plants for therapeutic purposes is called phytotherapy and its use is increasing among the general population, researchers and health professionals. One of the popular applications is the use of infusions for nephrological alterations, especially in the formation of calculi, or even kidney stones. Thus, in view of the great
} 
popular use of infusions, this work aims to evaluate the toxicity and hydrogenic infusion potential of the stem of Equisetum arvense L. (Horsetail), flowers of Hibiscus sabdariffa (Hibiscus) and leaves of Persea americana (avocado). For experimental evaluation, samples of natural products were obtained commercially and the preparation of infusions was added to water and heated to a boiling point. For toxicity testing, $300 \mu \mathrm{L}$ of the infusion was added to a 96-well culture plate at room temperature and one seed per well of Allium cepa was inoculated. of a peagometer, measurements of the $\mathrm{pH}$ value were carried out for 96 hours. No changes in germination and growth were identified in the tested infusions. As for the hydrogenic potential, the infusion of Horsetail (E. arvense) showed acidification of the medium by $10 \%$, while Hibiscus (H. sabdariffa) had $64 \%$ acidification and the avocado leaves had $21 \%$ acidification. Based on what has been demonstrated, the consumption of infusions of Horsetail, Hibiscus flowers and Avocado leaves proved to be safe against the Allium cepa test and promising for the treatment of alkaline urolithiasis, in addition to the antioxidant effects present in the literature. However, it can be harmful in cases of acid urolithiasis formation.

Keywords: Traditional medicine; Herbal medicine; Phytomedicine; Urolithiasis.

\section{Resumen}

En la medicina moderna, el uso de plantas con fines terapéuticos se denomina fitoterapia y su uso está aumentando entre la población en general, investigadores y profesionales de la salud. Una de las aplicaciones más populares es el uso de infusiones para alteraciones nefrológicas, especialmente en la formación de cálculos, o incluso cálculos renales. Así, ante el gran uso popular de las infusiones, este trabajo tiene como objetivo evaluar la toxicidad y el potencial hidrogénico de la infusión del tallo de Equisetum arvense L. (Cola de caballo), flores de Hibiscus sabdariffa (Hibiscus) y hojas de Persea americana (aguacate). Para la evaluación experimental, se obtuvieron muestras de productos naturales comercialmente y la preparación de infusiones se añadió al agua y se calentó a punto de ebullición. Para las pruebas de toxicidad, se añadieron $300 \mu \mathrm{L}$ de la infusión a una placa de cultivo de 96 pocillos a temperatura ambiente y se inoculó una semilla por pocillo de Allium cepa. De un peagómetro, se realizaron mediciones del valor de $\mathrm{pH}$ durante 96 horas. No se identificaron cambios en la germinación y el crecimiento en las infusiones probadas. En cuanto al potencial hidrogénico, la infusión de Cola de Caballo (E. arvense) mostró una acidificación del medio en un 10\%, mientras que Hibiscus (H. sabdariffa) tuvo una acidificación del 64\% y las hojas de aguacate un $21 \%$ de acidificación. Con base en lo demostrado, el consumo de infusiones de Cola de Caballo, Flores de Hibisco y Hojas de Aguacate demostró ser seguro frente al test de Allium cepa y prometedor para el tratamiento de la urolitiasis alcalina, además de los efectos antioxidantes presentes en la literatura. Sin embargo, puede ser perjudicial en casos de formación de urolitiasis ácida.

Palabras clave: Medicina tradicional; Herbal medicine; Fitoterapia; Urolitiasis.

\section{Introdução}

Na medicina moderna a utilização de plantas com fins terapêuticos é chamado fitoterapia e sua utilização é crescente frente a população em modo geral, pesquisadores e profissionais da área da saúde (Rosa et al., 2011; Junior et al., 2019). A fitoterapia é utilizada a séculos por diversas populações ao redor do mundo, podendo ser utilizado raízes, caules, folhas, flores e frutos (Lazarou \& Heinrich, 2019).

A Organização Mundial da Saúde (OMS), em 1978 disse que 80\% da população dos países em desenvolvimento utilizam práticas tradicionais básicas de saúde, como citado na Declaração de Alma-Ata (OMS, 1979). Tal prática vem sendo integrada em diversas culturas, como no Brasil, que indicou a utilização de produtos naturais e a fitoterapia como método alternativo de tratamento em 1986, durante a $8^{\text {a }}$ Conferência de Saúde, no emprego destes produtos em programas de atenção básica a saúde (Alves \& Silva, 2003; Rosa et al., 2011). Contudo, com o advento da medicina moderna e novas técnicas cientificas, estudos passaram a demonstrar que alguns produtos naturais não possuíam o efeito popular atribuído ou, ainda, apresentam efeitos nocivos à saúde (Tesser et al., 2018).

Uma das afecções tratadas popularmente com o uso de infusões é a alteração nefrológica em região de córtex renal na formação de cálculos, ou ainda, litíase renal. A mesma se dá predominantemente em pacientes do sexo masculino, entre a terceira e quarta década de vida, porém, não é incomum em pacientes mais novos e do sexo feminino (Jung et al., 2018; Lopes et al., 2021). A formação da litíase renal é multifatorial, podendo estar envolvida exposição a climas quentes, dietas ricas em proteína animal e sódio, sedentarismo. Pacientes negros não hispânicos e hispânicos apresentam menor incidência de formação de litíase renal (Scales et al., 2012; Ryu et al., 2018; Cassiano et al., 2021). 
Assim, frente a grande utilização popular de infusões o presente trabalho objetiva a avaliação de toxicidade e do potencial hidrogeniônico de infusão do caule de Equisetum arvense L. (Cavalinha), das flores de Hibiscus sabdariffa (Hibisco) e folhas de Persea americana (abacate).

\section{Metodologia}

\subsection{Obtenção da planta}

Para avaliação experimental, as amostras de Equisetum arvense L. (Cavalinha), das flores de Hibiscus sabdariffa (Hibisco) e folhas de Persea americana (abacate) foram obtidas de forma comercial em estabelecimento na cidade de Franca, São Paulo, Brasil com certificado de padrão de sanidade. A presença de líquidos ou alterações no aspecto das folhas e flores secas, indicando mal controle biológico de fungos e bactérias foi utilizado como critério de exclusão.

\subsection{Preparo das infusões}

Para o preparo das infusões do caule de Equisetum arvense L. (Cavalinha), das flores de Hibiscus sabdariffa (Hibisco) e folhas de Persea americana (abacate), foi adicionado água, da rede pública da cidade de Franca, São Paulo, Brasil, em recipiente de alumínio e levado a aquecimento até ponto de fervura. Posteriormente, $200 \mathrm{~mL}$ de água fervente foi transferida para recipiente de vidro e adicionados $100 \mathrm{~g}$ de folhas secas. O recipiente foi abafado com tampa para o preparo da infusão. Após 10 minutos, a infusão foi filtrada em papel filtro comercial.

\subsection{Teste de toxicidade}

Em placa de cultivo de 96 poços foram adicionados $300 \mu \mathrm{L}$ da infusão em temperatura ambiente (aproximadamente $25^{\circ} \mathrm{C}$ ) e inoculado uma semente por poço de Allium cepa (Feltrin Seeds) para avaliação de toxicidade pelo teste de germinação conforme metodologia descrita por Iganci et al. (2006). Como controle veículo foi utilizado água que passou no mesmo processo das infusões e controle positivo foi utilizado paracetamol (EMS S.A) a $50 \mathrm{mg} / \mathrm{mL}$, totalizando 9 sementes por tratamento. As placas de cultivo foram mantidas em ambiente fechado, protegido da luz, em temperatura ambiente (aproximadamente $25^{\circ} \mathrm{C}$ ), sendo a germinação avaliada no $7^{\circ}$ e $14^{\circ}$ dia.

A viabilidade foi obtida pela seguinte fórmula [(Tratado - controle positivo) / (controle negativo - controle positivo)] *100, e a taxa de crescimento avaliado a partir do escore, 1 germinou, 2 crescimento pequeno, 3 crescimento mediano, 4 bom crescimento.

\subsection{Teste de variação de $\mathrm{pH}$}

Para realização do teste de potencial hidrogeniônico de E. arvense, $H$. sabdariffa e $P$. americana, as infusões foram transferidas para recipiente de vidro. Com o auxílio de um peagâmetro foram realizadas aferições do valor de pH durante 96 horas. Para garantia dos resultados, o peagâmetro foi calibrado com soluções alcalina e ácida antes do início do experimento, e lavado com água destilada entre cada mensuração. Para evitar alterações o mesmo ainda foi limpo com papel filtro.

\subsection{Avaliação estatística}

O escore absoluto (escore de germinação x escore de crescimento) foi calculado e expresso para comparação final do teste de toxicidade, com variação de 0 (100\% de toxicidade) e 400 (100\% de viabilidade). Os resultados foram avaliados estatisticamente pelo teste de Kruskal-Wallis e múltiplas comparações pelo teste de Dunn's através de sistema GraphPad Prism 6 , sendo os resultados considerados significativos quando $\mathrm{p}<0,05$. 


\section{Resultados e Discussão}

Com o advento da medicina alopática a cultura fitoterápica tende a diminuir, entretanto, a sua utilização frente a classes socioeconômicas menos favorecida é crescente devido alto custo de medicamentos alopáticos. A utilização incorreta pode acarretar em problemas a saúde da população assistida ou ainda, agravo do processo patológico de infecções já instaladas (Santos et al., 2011; Almeida et al., 2020).

Nos dados da Figura 1, são representados o perfil de toxicidade das infusões a partir do crescimento das sementes de Allium cepa. Como esperado, o controle positivo, $0.1 \pm 0.3$, significativamente diferiu do controle negativo, $2.9 \pm 0.8$ em p<0,05. Já em relação as infusões, não foram observadas diferenças significativas em relação ao controle negativo.

Figura 1 - Teste de Germinação de Allium cepa depois de 14 dias de germinação em infusões populares. CN - controle negative (água da rede pública), CP - controle positivo $(50 \mathrm{mg} / \mathrm{mL}$ de paracetamol) * sinalizam diferença estatisticamente $(\mathrm{p}<0.001)$ quando comparado ao controle negativo.

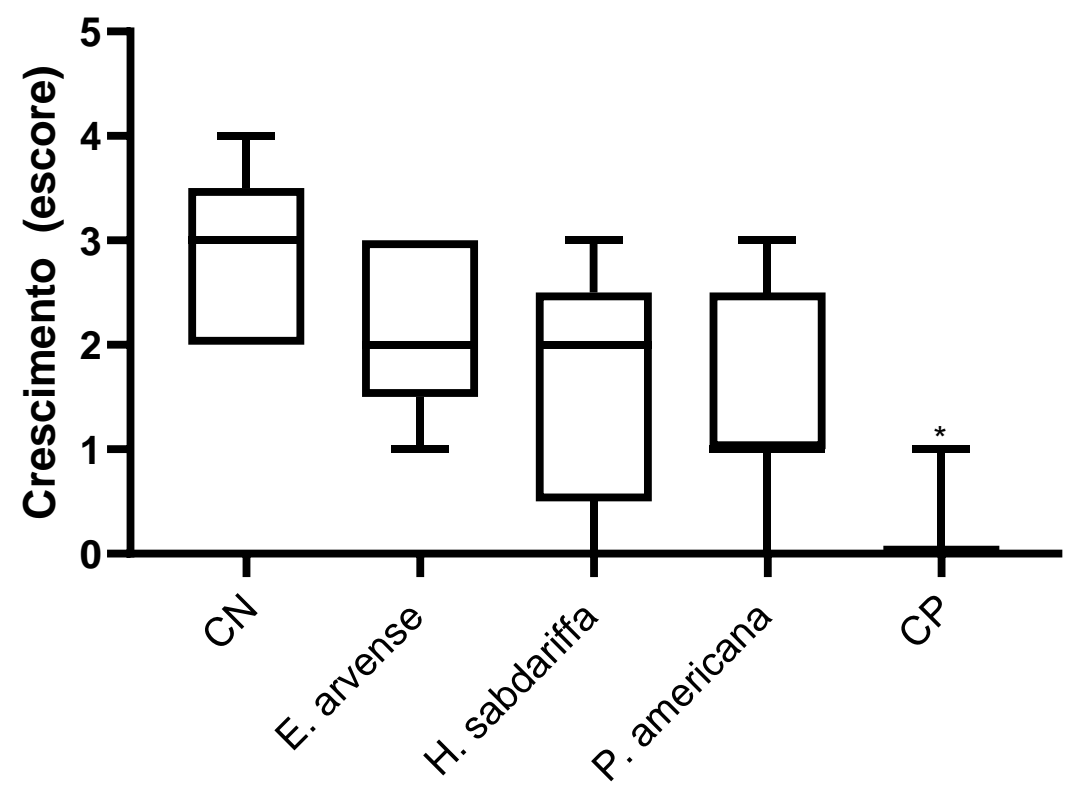

Fonte: Autores.

A ausência de toxicidade das infusões avaliada pelo teste de germinação em Allium cepa é corroborada pelos dados da literatura, sendo observado que as infusões de cavalinha (Baracho et al., 2009), do hibisco (Gad et al., 2020) e das folhas de abacate (Nicolella et al., 2017) não apresentam toxicidade. Além disso, a ausência de toxicidade pode estar relacionada com os potenciais antioxidantes da cavalinha (Masłowski et al., 2020), do hibisco (Chiaino et al., 2020) e do abacate (Wang et al., 2020), que podem ser atribuídas aos flavonoides e ácidos fenólicos que os frutos apresentam (Masłowski et al., 2020).

Quanto ao potencial hidrogeniônico sobre metodologia analítica, os dados da Figura 2, apresentam a mensuração do pH pelo período de $96 \mathrm{hs}$ das três infusões testadas, frente ao controle (água da rede pública). A infusão de Cavalinha (E. arvense) na hora zero, ou seja, após o preparo da infusão, apresentou acidificação do meio em $10 \%$ do valor do pH quando comparado a água (pH de 7,2 \pm 0,1), Hibisco (H. sabdariffa) apresentou a maior alteração, com 64\% de acidificação do meio $(2,8 \pm 0,01)$ e as folhas de abacate apresentaram acidificação de $21 \%$ (pH de 6,3 $\pm 0,01)$.

Nas avaliações subsequentes do pH das infusões observou-se que o pH da água não sofre variações ao longo do tempo $(8,0 \pm 0,1)$, demonstrando assim, que a água não interfere no $\mathrm{pH}$ ao longo do tempo. Quanto a infusão de cavalinha, houve uma 
variação de $23 \%$ frente a hora zero da infusão e $31 \%$ frente a água $(5,5 \pm 0,1)$ demonstrando que a acidificação se altera com o tempo. Situação igual quando avaliado a infusão das folhas de abacate, no qual apresenta $6 \%$ frente a hora zero da infusão e $26 \%$ frente a água $(5,9 \pm 0,01)$. Já em relação a infusão das folhas de hibisco não é observado variação, demonstrando ausência de efetividade frente a acidificação. Após o período de 96 horas, as amostras não apresentaram alterações quanto a sua coloração ou ainda, presença de crescimento de microrganismos visíveis.

Figura 2 - Teste de Potencial Hidrogeniônico $(\mathrm{pH})$ em metodologia analítica de infusões populares. $\mathrm{CN}$ - controle negativo (água da rede pública) e infusões de Equisetum arvense L. (Cavalinha), das flores de Hibiscus sabdariffa (Hibisco) e folhas de Persea americana (abacate).

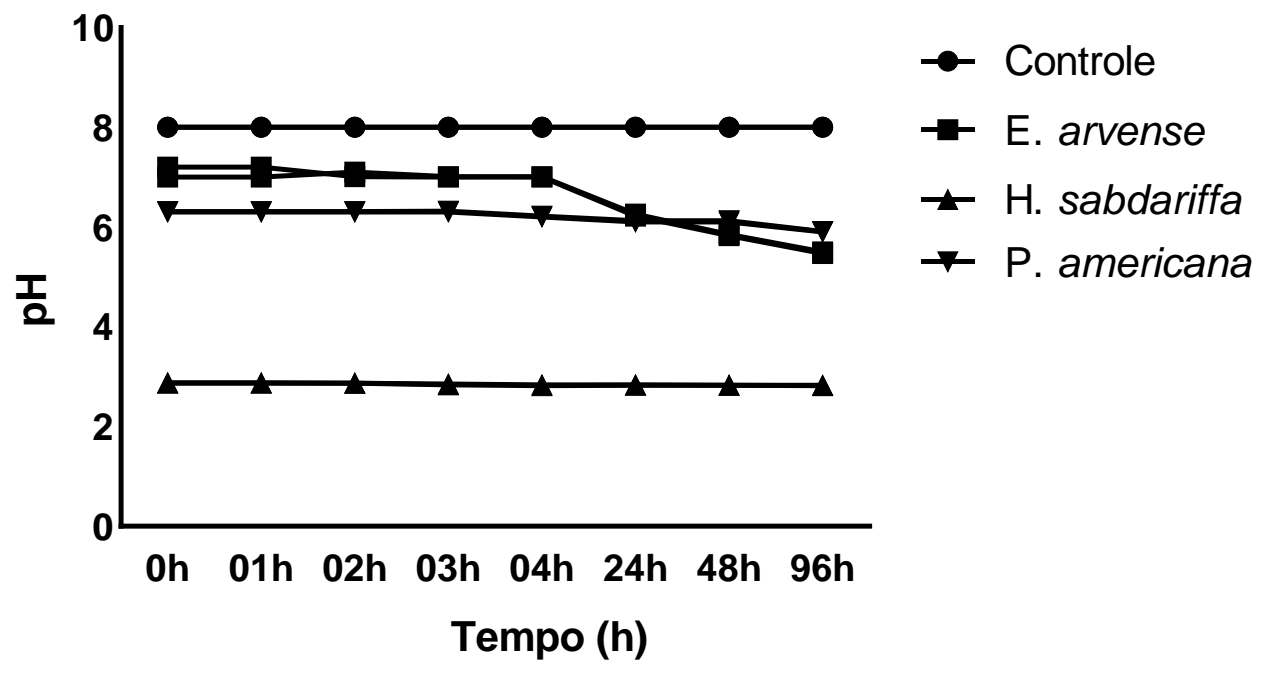

Fonte: Autores.

Efeitos adversos são relacionados com metabólitos não ligados a atividade biológica, interação e sinergismo com outros compostos presentes nas plantas, ou ainda, interação com patologias pré-existentes, além da associação com medicamentos alopáticos, condições de colheita, secagem e armazenamento poderem alterar as propriedades do produto (Lazarou \& Heinrich, 2019; Park et al., 2019). É de suma importância a avaliação da composição fitoquímica de produtos naturais, assim como efeitos adversos causados pelas mesmas (Varanda, 2009).

A formação dos cálculos renais tem sua gênese a partir de fatores externos, como temperatura, ingestão hídrica e dieta consumida (Cruces et al., 2013). Sabe-se que os principais cristais formados em região de córtex renal se dão pela acidificação (ácido úrico e urato amorfo) ou alcalinização (fosfato amorfo e oxalato de cálcio) com a não solubilização dos compostos orgânicos e inorgânicos (Carvalho \& Carvalho, 2018).

Os dados encontrados no presente trabalho, demonstra que a atividade das infusões testadas, quando ingeridas com acompanhamento médico, pode auxiliar na dissolução dos cálculos alcalinos. Tal ação se dá pela composição química de cada infusão, no qual, pode alterar o pH renal e auxiliar na diminuição, eliminação ou não formação do cálculo renal. A literatura traz informações acerca de técnicas não convencionais para tratamento além do uso de litotripsia (Lopata et al., 2017).

Em contrapartida, a grande preocupação da medicina tradicional é o consumo exagerado e sem acompanhamento especializado, podendo ocorrer piora do quadro do paciente. Os dados de avaliação de $\mathrm{pH}$ demonstram a acidificação das três infusões, podendo ser prejudicial na formação de novos cálculos renais de origem ácida (Lopata et al., 2017), sendo a principal atividade não cirúrgica para tratamento de urolitíase a ingestão em grandes quantidades de líquidos na intenção de aumentar o débito urinário (Torricelli et al., 2020). 


\section{Conclusão}

Frente ao demonstrado, o consumo das infusões de Cavalinha, flores de Hibisco e de folhas de Abacate se mostrou seguro frente ao teste de Allium cepa e promissor para tratamento de urolitíase alcalina, além dos efeitos antioxidantes presentes na literatura. No entanto, pode ser prejudicial em casos da formação de urolitíase ácida.

\section{Referências}

Almeida, S. de, Branquinho, G. N., Santos, L. A. S., Silva, L. H. D. da, Cruz, R. C. R., Dias, F. G. G., \& Furtado, R. A. (2020). Avaliação do potencial quimioprotetor do fruto de Psidium guajava contra os efeitos genotóxicos da doxorrubicina. Cadernos Saúde Coletiva, 28 , 422-425. https://doi.org/10.1590/1414-462X202028030501

Alves, A. R., \& Silva, M. J. P. da. (2003). O uso da fitoterapia no cuidado de crianças com até cinco anos em área central e periférica da cidade de São Paulo. Revista da Escola de Enfermagem da USP, 37(4), 85-91. https://doi.org/10.1590/S0080-62342003000400010

Baracho, N. C. do V., Vicente, B. B. V., Arruda, G. D. S., Sanches, B. C. F., \& Brito, J. de. (2009). Study of acute hepatotoxicity of Equisetum arvense L. in rats. Acta Cirurgica Brasileira, 24(6), 449-453. https://doi.org/10.1590/s0102-86502009000600005

Carvalho, M., \& Carvalho, M. (2018). Urinary pH in calcium oxalate stone formers: Does it matter? Brazilian Journal of Nephrology, 40(1), 6-7. https://doi.org/10.1590/1678-4685-jbn-2018-00010002

Cassiano, L. C., Feitosa, F. L. L., Lago, V. J., Almeida Junior, S., Maniglia, F. P., \& Franco, G. S. (2021). O uso de creatina monohidratada e o possível compromentimento na disfunção renal: Revisão narrativa | Revista Eletrônica Acervo Saúde. Revista Eletrônica Acervo Saúde, 13 (8), e8609.

Chiaino, E., Micucci, M., Cosconati, S., Novellino, E., Budriesi, R., Chiarini, A., \& Frosini, M. (2020). Olive Leaves and Hibiscus Flowers Extracts-Based Preparation Protect Brain from Oxidative Stress-Induced Injury. Antioxidants (Basel, Switzerland), 9(9). https://doi.org/10.3390/antiox9090806

Cruces, I. L., Patelli, T. H. C., Tashima, C. M., \& Mello-Peixoto, E. C. T. (2013). Using medicinal plants in the control of urolithiasis. Revista Brasileira de Plantas Medicinais, 15(4), 780-788. https://doi.org/10.1590/S1516-05722013000500020

Gad, F. A.-M., Farouk, S. M., \& Emam, M. A. (2020). Antiapoptotic and antioxidant capacity of phytochemicals from Roselle (Hibiscus sabdariffa) and their potential effects on monosodium glutamate-induced testicular damage in rat. Environmental Science and Pollution Research International. https://doi.org/10.1007/s11356-020-10674-7

Iganci, J. R. V., Bobrowski, V. L., Heiden, G., Stein, V. C., \& Rocha, B. H. G. (2006). Efeito do extrato aquoso de diferentes espécies de boldo sobre a germinação e indice mitótico de allium cepa L. São Paulo, 4.

Jung, J. S., Han, C. H., \& Bae, S. (2018). Study on the prevalence and incidence of urolithiasis in Korea over the last 10 years: An analysis of National Health Insurance Data. Investigative and Clinical Urology, 59(6), 383-391. https://doi.org/10.4111/icu.2018.59.6.383

Junior, S. de A., Silva, F. C. da, Moreira, N. I. T., Bulgo, D. C., Oliveira, L. N., Rodrigues, A. A., Silva, G. H. V., Gonçalves, C. R., Souza, B. C. de, Pereira, L. A., Melo, M. R. S. de, Nakamura, F. de C., \& Andrade, G. (2019). Bases pedagógicas em curso profissionalizante de Farmácia e Laboratório Clínico como apoio na construção profissional do indivíduo. Revista Eletrônica Acervo Saúde, 25, e649-e649. https://doi.org/10.25248/reas.e649.2019

Lazarou, R., \& Heinrich, M. (2019). Herbal medicine: Who cares? The changing views on medicinal plants and their roles in British lifestyle. Phytotherapy Research: PTR, 33(9), 2409-2420. https://doi.org/10.1002/ptr.6431

Lopata, V. J., Hofelmann, D. A., Spezia, J., \& Hauser, A. B. (2017). Análise de dados clínicos e laboratoriais associados à litíase urinária em pacientes de um laboratório de análises clínicas. Visão Acadêmica, 17(3), Article 3. https://doi.org/10.5380/acd.v17i3.48804

Lopes, L. G., Csonka, L. A., Castellane, J. A. S., Oliveira, A. W., Almeida-Júnior, S. de, Furtado, R. A., Tararam, C., Levy, L. O., Crivellenti, L. Z., Moretti, M. L., Giannini, M. J. S. M., \& Pires, R. H. (2021). Disinfectants in a Hemodialysis Setting: Antifungal Activity Against Aspergillus and Fusarium Planktonic and Biofilm Cells and the Effect of Commercial Peracetic Acid Residual in Mice. Frontiers in Cellular and Infection Microbiology, 11, 227. https://doi.org/10.3389/fcimb.2021.663741

Masłowski, M., Miedzianowska, J., Czylkowska, A., \& Strzelec, K. (2020). Horsetail (Equisetum Arvense) as a Functional Filler for Natural Rubber Biocomposites. Materials (Basel, Switzerland), 13(11). https://doi.org/10.3390/ma13112526

Nicolella, H. D., Neto, F. R., Corrêa, M. B., Lopes, D. H., Rondon, E. N., Dos Santos, L. F. R., de Oliveira, P. F., Damasceno, J. L., Acésio, N. O., Turatti, I. C. C., Tozatti, M. G., Cunha, W. R., Furtado, R. A., \& Tavares, D. C. (2017). Toxicogenetic study of Persea americana fruit pulp oil and its effect on genomic instability. Food and Chemical Toxicology: An International Journal Published for the British Industrial Biological Research Association, 101, 114-120. https://doi.org/10.1016/j.fct.2017.01.009

Park, S., In Hwang, S., Kim, J., Hwang, S., Kang, S., Yang, S., Kim, J., Kang, W., Kim, K.-H., Han, D. W., \& Paik, Y.-H. (2019). The therapeutic potential of induced hepatocyte-like cells generated by direct reprogramming on hepatic fibrosis. Stem Cell Research \& Therapy, 10(1), 21. https://doi.org/10.1186/s13287-018-1127-3

Rosa, C. da, Câmara, S. G., \& Béria, J. U. (2011). Representações e intenção de uso da fitoterapia na atenção básica à saúde. Ciência \& Saúde Coletiva, 16, 311-318. https://doi.org/10.1590/S1413-81232011000100033

Ryu, H. Y., Lee, Y. K., Park, J., Son, H., \& Cho, S. Y. (2018). Dietary risk factors for urolithiasis in Korea: A case-control pilot study. Investigative and Clinical Urology, 59(2), 106-111. https://doi.org/10.4111/icu.2018.59.2.106 
Research, Society and Development, v. 10, n. 15, e164101522634, 2021

(CC BY 4.0) | ISSN 2525-3409 | DOI: http://dx.doi.org/10.33448/rsd-v10i15.22634

Santos, R. L., Guimaraes, G. P., Nobre, M. S. C., \& Portela, A. S. (2011). Análise sobre a fitoterapia como prática integrativa no Sistema Único de Saúde. Revista Brasileira de Plantas Medicinais, 13(4), 486-491. https://doi.org/10.1590/S1516-05722011000400014

Scales, C. D., Smith, A. C., Hanley, J. M., Saigal, C. S., \& Urologic Diseases in America Project. (2012). Prevalence of kidney stones in the United States. European Urology, 62(1), 160-165. https://doi.org/10.1016/j.eururo.2012.03.052

Tesser, C. D., Sousa, I. M. C. de, \& Nascimento, M. C. do. (2018). Práticas Integrativas e Complementares na Atenção Primária à Saúde brasileira. Saúde em Debate, 42, 174-188. https://doi.org/10.1590/0103-11042018s112

Torricelli, F. C., Reichard, C., \& Monga, M. (2020). Urolithiasis in complicated inflammatory bowel disease: A comprehensive analysis of urine profile and stone composition. International Urology and Nephrology. https://doi.org/10.1007/s11255-020-02649-x

Varanda, E. A. (2009). Atividade mutagênica de plantas medicinais. Revista de Ciências Farmacêuticas Básica e Aplicada, 27(1), 1-7-7.

Wang, L., Tao, L., Hao, L., Stanley, T. H., Huang, K.-H., Lambert, J. D., \& Kris-Etherton, P. M. (2020). A Moderate-Fat Diet with One Avocado per Day Increases Plasma Antioxidants and Decreases the Oxidation of Small, Dense LDL in Adults with Overweight and Obesity: A Randomized Controlled Trial. The Journal of Nutrition, 150(2), 276-284. https://doi.org/10.1093/jn/nxz231 